\title{
Socioeconomic influences on back problems in the community in Britain
}

Arthritis and

Rheumatism Council

Epidemiology

Research Unit,

University of

Manchester, Stopford

Building, Oxford

Road, Manchester

M13 9PT

P R Croft

Nuffield Institute for Health and

Department of

Clinical Medicine,

University of Leeds,

Leeds

A S Rigby

Correspondence to:

Dr P R Croft.

Accepted for publication August 1993

\author{
Peter R Croft, Alan S Rigby
}

\begin{abstract}
Objective - To determine the association between measures of socioeconomic status and reported back pain in a national sample survey of the adult population of Britain.

Design - Secondary analysis of a cross sectional interview survey (the Health and Lifestyle Survey).

Setting - Households in England, Wales, and Scotland.

Subjects - Those 9003 adults aged 18 years and above who agreed to an interview, from a study base of 12254 private households that had been identified in a three stage sampling procedure based on electoral registers. Subjects who reported back pain in the month before interview were compared with all those who stated they had not experienced this symptom. Measures and results - Women whose households were in the lowest income category were more likely to report back pain than those in the highest income group (odds ratio $1 \cdot 6,95 \%$ confidence interval (CI) $1 \cdot 2,2 \cdot 1)$. In addition, women with no formal educational qualification were more likely to report back pain than women who had a qualification (odds ratio $1 \cdot 5,95 \% \mathrm{CI} 1 \cdot 0,2 \cdot 1)$. These associations were not explained by smoking, obesity, and coexistent depressive symptoms. In men the only socioeconomic link with back pain seemed to be manual occupation.
\end{abstract}

Conclusions - These findings confirm the higher burden of back pain in the socially disadvantaged, but suggest that this cannot yet be explained by known risk factors for back trouble.

( $\mathcal{F}$ Epidemiol Community Health 1994;48:166-170)

Social class differences in mortality have highlighted inequalities in health and indicated potential causes of fatal diseases. ${ }^{1}$ Social class differences in the occurrence of non-fatal conditions, such as back pain, could also provide clues to aetiology, but data about these are more limited. It is important to identify preventable causes of morbidity as well as mortality since conditions which disable but do not kill have a huge economic and social impact on the health of communities. For instance, one in 20 British adults consult their family doctor each year with a new episode of back pain ${ }^{2}$; it is the most common reason for working days lost through sickness (Department of Social Security, personal communication) and the predom- inant cause of disability in adults under 60 years. ${ }^{3}$

There are a number of reasons why socioeconomic differences may play an important role in the aetiology of back pain. Certain occupational factors have been associated with back pain, notably the manual lifting of heavy weights. ${ }^{4}$ There is some evidence linking backache with behaviours that differ across social groupings such as cigarette smoking ${ }^{5}$ and stress and psychiatric morbidity. ${ }^{6}$ Some studies have found that constitutional factors such as height ${ }^{4}$ and weight ${ }^{5}$ are associated with back trouble; these also vary with social class. Although the evidence relating to such risks is far from consistent, ${ }^{7}$ it provides a basis for interpreting socioeconomic differences in back pain occurrence.

Most episodes of back pain are not reported to the medical services. Consulting a general practitioner is related not only to the severity of back pain, ${ }^{9}$ but also to the patient's occupation and the need for sickness certification. Consultations for back pain are therefore likely to have a different social class distribution compared with self reported back pain in the community. We have used data from a large sample of the British adult population, the Health and Lifestyle Survey, ${ }^{8}$ to examine if there is a link between self reported back pain and social class, household income, or educational attainment in men and women, and how this relates to height, weight, smoking, and measures of psychological stress.

We have also compared the results of this analysis with those from the Royal College of General Practitioners' Third National Morbidity Survey in General Practice, in which data based on consultations in primary care were linked to census data relating to occupational class. ${ }^{10}$

\section{Methods}

The Health and Lifestyle Survey was conducted in 1984-85 with its principal objective to "examine the relationship of lifestyles, behaviours and circumstances to the physical and mental health of a large representative sample of the British population". ${ }^{8}$ It consisted of a national sample survey of adults aged 18 years and over living in private households in England, Wales, and Scotland. The sampling frames were the electoral registers of the three countries, and a random selection of household addresses was compiled using a three stage sampling design. In each household one individual aged 18 years and above was selected from all those resident at the address using standard sampling techniques. In total, 9003 
Table 1 Prevalence of self reported back pain in a national population sample of 9003 adults in Great Britain, 1984-85

\begin{tabular}{|c|c|c|c|c|c|c|c|c|c|}
\hline \multirow[b]{2}{*}{$\begin{array}{l}\text { Age } \\
(y)\end{array}$} & \multicolumn{3}{|c|}{ All subjects } & \multicolumn{3}{|c|}{ Women } & \multicolumn{3}{|l|}{ Men } \\
\hline & Total & $\begin{array}{l}\text { No with } \\
\text { back pain }\end{array}$ & $(\%)$ & Total & $\begin{array}{l}\text { No with } \\
\text { back pain }\end{array}$ & $(\%)$ & Total & $\begin{array}{l}\text { No with } \\
\text { back pain }\end{array}$ & $\left(0_{0}\right)$ \\
\hline $\begin{array}{l}<25 \\
25-34 \\
35-44 \\
45-54 \\
55-64 \\
65-74 \\
75+\end{array}$ & $\begin{array}{r}1160 \\
1700 \\
1752 \\
1386 \\
1390 \\
1040 \\
575\end{array}$ & $\begin{array}{l}161 \\
251 \\
309 \\
294 \\
290 \\
243 \\
152\end{array}$ & $\begin{array}{l}(13 \cdot 8) \\
(14 \cdot 8) \\
(17 \cdot 6) \\
(21 \cdot 1) \\
(20 \cdot 9) \\
(23 \cdot 3) \\
(26 \cdot 4)\end{array}$ & $\begin{array}{r}625 \\
976 \\
1007 \\
792 \\
762 \\
592 \\
344\end{array}$ & $\begin{array}{r}98 \\
151 \\
186 \\
186 \\
175 \\
165 \\
107\end{array}$ & $\begin{array}{l}(15.7) \\
(15.5) \\
(18.5) \\
(23.5) \\
(22.9) \\
(27.9) \\
(31.1)\end{array}$ & $\begin{array}{l}535 \\
724 \\
745 \\
594 \\
628 \\
448 \\
231\end{array}$ & $\begin{array}{r}63 \\
100 \\
123 \\
108 \\
115 \\
78 \\
45\end{array}$ & $\begin{array}{l}(11.8) \\
(13.8) \\
(16.5) \\
(18.2) \\
(18.3) \\
(17.4) \\
(19.5)\end{array}$ \\
\hline All ages & 9003 & 1700 & $(18.9)$ & 5098 & 1068 & $(20.9)$ & 3905 & 632 & $(16 \cdot 2)$ \\
\hline
\end{tabular}

individuals from a study base of 12254 private households were eventually interviewed by trained nurses. This represented a $73.5 \%$ response rate.

The data collected were summarised in a publication, ${ }^{8}$ and were made available to the public domain in the Economic and Social Sciences Research Council Data Archive at the University of Essex. ${ }^{9}$ We extracted the variables relevant to this study from the main dataset.

Cases of individuals with back pain were defined as all those subjects who answered positively to the question "Within the last month have you suffered from any problems with a bad back?".

Scoioeconomic status was investigated using three separate measures from the survey database:

(1) Occupational class based on the Registrar General's Classification of Occupations. ${ }^{11}$ For men and divorced or single women, their own current job was the basis of classification; for those who had retired or were currently unemployed, past or usual occupation was used. Married women were classified on the same scale but according to their husband's occupation.

This classification is as follows:

I - professional occupations;

II - intermediate occupations eg nursing;

III-NM - skilled occupations: nonmanual;

III-M - skilled occupations: manual;

IV - partly skilled occupations;

$\mathrm{V}$ - unskilled occupations.

(2) Individuals were grouped by income level, measured as the current monthly income in $£$ s sterling for the household in which they lived.

(3) Educational attainment was estimated by the highest qualification achieved. General Certificate of Education Ordinary ("O') level or Certificate of Secondary Education are examinations taken at secondary school at age 15-16 years; advanced ("A") level exams at age $17-18$ years.

Other potential risk factors for back problems which we investigated were current and former cigarette smoking, including the number of cigarettes smoked daily; weight and height, measured by the nurses who carried out interviews; anxiety and depression, as measured by scores on the 30 item General Household Questionnaire (GHQ). ${ }^{12}$ This latter measure is a validated instrument for use in the general population; a score of 5 or more is considered to indicate likely clinical depression.

STATISTICAL ANALYSIS

Individuals with back pain were compared with the remainder of the survey population using the GLIM statistical programme. ${ }^{13}$ Associations with self reported back pain were calculated as odds ratios (with $95 \%$ confidence intervals (CI)) by unconditional logistic regression, adjusting for age unless otherwise stated. Men and women were analysed separately.

Weight and body mass index were categorised into approximate quintiles and the height into quartiles; this was done separately for men and women. Both the number of cigarettes smoked and household income were analysed using the categories generated in the original dataset.

\section{Results}

In this population the crude prevalence of self reported "back problems in the past month" was $18.9 \%$. Age and sex stratified prevalences of back pain are shown in table 1 .

\section{BACK PAIN AND SOCIAL STATUS}

When compared with non-manual workers, subjects in the manual occupations were more likely to have reported back pain during the past month (table $2 \mathrm{~A}$ ), although there was no clear trend of risk across levels of the Registrar General's occupational classification.

Those who were unemployed or retired were no different with regard to their reporting of recent back problems compared with those who were working. The chronically sick or disabled had a high prevalence of recent back problems $(43 \%)$, compared with those in full time employment. "Housekeepers" were significantly more likely to have reported back problems than those working outside the home (OR $1 \cdot 4,95 \%$ CI $1 \cdot 3,1 \cdot 7$, adjusted for age and sex). ("Housekeepers" were women or men below retirement age who gave this as their occupation and who were not otherwise in the labour market.)

The association of reported back problems with household income is shown in table $2 \mathrm{~B}$. Women whose households were in the lowest quintile of monthly income were more likely to report back pain than those in the highest income category (OR 1.6). The trend across 
Table 2 Associations between self reported back pain and socioeconomic measures, summarised by odds ratios (OR) with their $95 \%$ confidence intervals (CI)

\begin{tabular}{|c|c|c|c|c|c|c|}
\hline \multirow[b]{2}{*}{ Category } & \multicolumn{3}{|c|}{ Women } & \multicolumn{3}{|l|}{ Men } \\
\hline & No & $O R^{*}$ & $(95 \% C I)$ & No & $O R^{*}$ & $(95 \% C I)$ \\
\hline \multicolumn{7}{|c|}{ A Social class (Registrar General's classification): } \\
\hline & 266 & 1.00 & & 198 & 1.00 & \\
\hline II & 1148 & 0.91 & $(0 \cdot 65,1 \cdot 29)$ & 860 & 0.93 & $(0.59,1.45)$ \\
\hline III-NM & 793 & 0.94 & $(0.66,1.35)$ & 472 & 0.99 & $(0.62,1.59)$ \\
\hline III-M & 1667 & 1.24 & $(0.90,1.72)$ & 1427 & $1 \cdot 15$ & $(0.76,1.75)$ \\
\hline IV & 861 & 1.33 & $(0.95,1.88)$ & 651 & 1.05 & $(0.69,1.64)$ \\
\hline $\mathrm{V}$ & 249 & 1.23 & $(0.80,1.88)$ & 229 & $1 \cdot 41$ & $(0.85,2.35)$ \\
\hline \multicolumn{7}{|c|}{ rling, per month for household): } \\
\hline$<=230$ & 935 & 1.55 & $(1 \cdot 17,2 \cdot 06)$ & 406 & 0.95 & $(0.65,1.39)$ \\
\hline $231-415$ & 1276 & 1.38 & $(1.05,1.80)$ & 917 & 1.02 & $(0.75,1.39)$ \\
\hline $416-750$ & 1243 & 1.32 & $(1.01,1.73)$ & 1214 & 0.94 & $(0.71,1.24)$ \\
\hline $751-995$ & 509 & 1.02 & $(0.73,1.43)$ & 513 & 0.83 & $(0.59,1 \cdot 17)$ \\
\hline$>=996$ & 541 & 1.00 & & 542 & 1.00 & \\
\hline \multicolumn{7}{|l|}{ C Education+: } \\
\hline $\begin{array}{l}\text { University degree } \\
\text { Professional }\end{array}$ & 262 & $1 \cdot 00$ & & 454 & $1 \cdot 00$ & \\
\hline qualification & 331 & $0 \cdot 83$ & $(0.52,1.30)$ & 51 & 0.77 & $(0.31,1.87)$ \\
\hline "A" level & 328 & 0.97 & $(0.62,1.53)$ & 626 & $1 \cdot 18$ & $(0.84,1.65)$ \\
\hline “O" level CSE & 1481 & $1 \cdot 26$ & $(0.88,1.81)$ & 936 & 0.95 & $(0.68,1.31)$ \\
\hline None & 2666 & 1.45 & $(1.02,2.05)$ & 1804 & $1 \cdot 19$ & $(0.89,1.59)$ \\
\hline
\end{tabular}

* All odds ratios were adjusted for age.

+ Adjusted for long term sickness/disability

+ Current highest qualification obtained.

Subjects with missing data were excluded.

Table 3 Associations between self reported back pain and smoking, body mass, and Table 3 Associations between self reported back pain and smoking, body mass, and
depression, summarised by odds ratios (OR) with their $95 \%$ confidence intervals (CI)

\begin{tabular}{|c|c|c|c|c|c|c|}
\hline \multirow[b]{2}{*}{ Category } & \multicolumn{3}{|c|}{ Women } & \multicolumn{3}{|l|}{ Men } \\
\hline & No & $O R^{*}$ & $(95 \% C I)$ & No & $O R^{*}$ & $(95 \% C I)$ \\
\hline \multicolumn{7}{|l|}{ Smoking status: } \\
\hline $\begin{array}{l}\text { Non-smoker } \\
\text { Current smoker }\end{array}$ & 2387 & $1 \cdot 00$ & & 1226 & 1.00 & \\
\hline $\begin{array}{l}\text { Current smoker } \\
\text { Ex-smoker }\end{array}$ & 1709 & 1.38 & $(1.18,1.62)$ & 1437 & $\begin{array}{l}1.29 \\
1.45\end{array}$ & $(1.12,1.74)$ \\
\hline \multirow{2}{*}{\multicolumn{6}{|c|}{ Cigarettes/dayt: }} & \\
\hline & & & & 1226 & 1.00 & \\
\hline $1-9$ & 755 & $1 \cdot 14$ & $(0.93,1.40)$ & 429 & 1.52 & $(1.13,2.05)$ \\
\hline $10-19$ & 1010 & 1.27 & $(1.06,1.53)$ & 880 & $1 \cdot 30$ & $(1.01,1.67)$ \\
\hline $20-29$ & 700 & 1.45 & $(1.18,1.77)$ & 892 & 1.39 & $(1.09,1.77)$ \\
\hline $30-39$ & 108 & 1.89 & $(1.23,2.91)$ & 202 & $1 \cdot 41$ & $(0 \cdot 95,2 \cdot 11)$ \\
\hline $40+$ & 67 & 1.90 & $(1 \cdot 12,3 \cdot 22)$ & 212 & 1.89 & $(1.31,2.72)$ \\
\hline \multicolumn{7}{|c|}{ Body mass index $\left(B M I=k g\right.$ per $\left.\mathrm{m}^{2}\right)$ : } \\
\hline$<=21 \cdot 0$ & 1247 & 1.00 & & 585 & 1.00 & \\
\hline $21 \cdot 1-22 \cdot 9$ & 1087 & $1 \cdot 16$ & $(0.94,1.44)$ & 738 & $1 \cdot 27$ & $(0.93,1.72)$ \\
\hline $23 \cdot 0-24 \cdot 6$ & 916 & $1 \cdot 18$ & $(0.95,1.47)$ & 855 & $1 \cdot 16$ & $(0.86,1.56)$ \\
\hline $24 \cdot 7-27 \cdot 3$ & 833 & 1.36 & $(1.09,1.70)$ & 969 & $1 \cdot 18$ & $(0.83,1.50)$ \\
\hline$>27.3$ & 734 & 1.45 & $(1 \cdot 16,1 \cdot 83)$ & 651 & 1.25 & $(0.92,1.71)$ \\
\hline \multicolumn{7}{|c|}{ General health questionnaire score (GHQ): } \\
\hline $1-4$ & 2432 & $1 \cdot 00$ & & 2121 & $\begin{array}{l}1.00 \\
1.63\end{array}$ & $(1.32,1.99)$ \\
\hline $5+$ & 1224 & 1.97 & $(1 \cdot 68,2 \cdot 32)$ & 790 & & \\
\hline
\end{tabular}

* All odds ratios were adjusted for age.

All odds ratios were adjusted for age.

Subjects with missing data were excluded.

Table 4 Association between self reported back pain and measures of socioeconomic status, summarised by odds ratios (OR) and $95 \%$ confidence intervals (CI)

\begin{tabular}{|c|c|c|c|c|}
\hline \multirow[b]{2}{*}{ Factor } & \multicolumn{2}{|c|}{ Women } & \multicolumn{2}{|l|}{ Men } \\
\hline & $O R^{*}$ & $(95 \% C I)$ & $O R^{*}$ & $(95 \% C I)$ \\
\hline \multicolumn{5}{|c|}{ Social class (Registrar General's classification): } \\
\hline 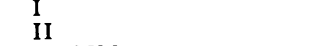 & $\begin{array}{l}1.00 \\
0.90\end{array}$ & $(0.64,1.28)$ & $\begin{array}{l}1.00 \\
0.94\end{array}$ & $(0.61,1.47)$ \\
\hline III-NM & 0.92 & $(0.64,1.34)$ & 0.99 & $(0.62,1.60)$ \\
\hline III-M & $1 \cdot 13$ & $(0.81,1.59)$ & 1.13 & $(0.74,1.72)$ \\
\hline IV & $1 \cdot 20$ & $(0.85,1.71)$ & 1.03 & $(0.72,1.53)$ \\
\hline $\mathrm{V}$ & $1 \cdot 10$ & $(0.70,1.66)$ & 1.39 & $(0 \cdot 83,2 \cdot 33)$ \\
\hline \multicolumn{5}{|c|}{ Education level (current highest qualification obtained): } \\
\hline University degree & $1.00^{\circ}$ & & 1.00 & \\
\hline Professional qualification & 0.79 & $(0 \cdot 50,1 \cdot 26)$ & 0.75 & $(0.31,1.84)$ \\
\hline "A" level & 1.04 & $(0.61,1.52)$ & $1 \cdot 19$ & $(0.85,1.68)$ \\
\hline “O” level/CSE & $1 \cdot 19$ & $(0.82,1.71)$ & 0.93 & $(0.67,1.29)$ \\
\hline None & $1 \cdot 27$ & $(0.89,1.81)$ & $1 \cdot 17$ & $(0.87,1.57)$ \\
\hline \multicolumn{5}{|c|}{ Income ( $£$ s sterling per month for household): } \\
\hline$<=230$ & & $(1.08,1.92)$ & 0.92 & $(0.64,1.33)$ \\
\hline $231-415$ & $1 \cdot 27$ & $(0.97,1.67)$ & 1.04 & $(0.78,1.40)$ \\
\hline $416-750$ & & $(0.94,1.63)$ & 0.95 & $(0.72,1.26)$ \\
\hline $751-995$ & 1.09 & $(0.71,1.39)$ & 0.82 & $(0.58,1.15)$ \\
\hline$>=996$ & 1.00 & & 1.00 & \\
\hline
\end{tabular}

* All odds ratios were adjusted for age, smoking, body mass index, and GHQ score. levels of income is significant $(p<0.01)$. In contrast there was no association between household income and back pain in men. Income levels were adjusted for age and chronic disability.

Women without formal educational qualifications were more likely to report back pain than those who had any form of higher education (table 2C). No similar association was apparent in men.

\section{OTHER RISK FACTORS}

Table 3 summarises the relationships between back pain and smoking, body mass index, and depression score. There was a significant association between regular current smoking and reported back pain (odds ration $1.4,95 \% \mathrm{CI}$ $1 \cdot 2,1 \cdot 6)$. The risk was similar for exsmokers. When all those who had ever smoked were analysed according to the quantity of cigarettes smoked per day, the likelihood of back pain being reported increased with the number of cigarettes smoked (odds ratio 1.9 , for those smoking 40 or more cigarettes per day relative to those who had never smoked). This trend was clearer for women than for men.

There was a weak but positive association between back pain and height in both men and women. In women there was a positive trend for back pain with weight and body mass index that was not seen in men.

Subjects in the survey with a score of 5 or more on the GHQ were more likely to have reported back problems during the past month than those who scored less than 5 . When the total possible score was considered as a categorical scale the link with back pain seemed stronger the higher the score.

INTER-RELATION OF CLASS, INCOME, SMOKING, DEPRESSION, AND BODY MASS INDEX

To explore the extent to which the socioeconomic differences in reporting of back pain might be confounded or explained by other factors we examined certain of the variables in a multivariate model to adjust for the effects of one variable upon another (table 4). Since effects had varied for women and men, this analysis was performed separately for the two sexes.

In women, the association with household income remained after adjusting for the effects of smoking, body mass index, and GHQ score. In fact estimates of association were hardly changed at all by their inclusion in the model. When educational attainment and income were considered together, there was no change in the size of the crude estimates. In men, the non-significant increase of risk restricted to unskilled manual workers (occupational class V) was similar to the crude effect after adjusting for smoking, body mass index, and GHQ score.

\section{Discussion}

We have analysed data from a large cross sectional survey of health and lifestyle in the 
British population, and shown that in women back problems are more likely to be reported by those from households with lower incomes and those who have no educational qualification. These associations were not explained by the effects of smoking, obesity, or coexistent depressive symptoms. In men, the only socioeconomic link seemed to be with unskilled manual labour.

Back problems were self reported and the question used was not specific - low back pain was not distinguished from other back pain, and so the data could well include symptoms arising from the cervical and upper thoracic spine as well as the lumbosacral region. The justification for examining the responses to this question in a large dataset is that nonspecific low back pain is the dominant back complaint in adults in the general population. It is important to consider, however, whether the responses to this question were biased with regard to the other variables we have examined. The interview schedule was long and it seems unlikely that there was differential reporting of one out of the many medical problems addressed. Although there may be a general propensity for some people to answer many questions positively, the independent effects observed for smoking, obesity, and income argue against this being responsible for the results presented here.

One rationale for examining socioeconomic influences on common symptoms is that any differences between social groups may be the effect of preventable environment or lifestyle risks. For example measures of social class, income and education may reflect smoking habits or obesity, which evidence suggests have a direct effect on back pain. Following this argument smoking, obesity, and stress are not classic "confounders" of the observed association of back pain and social class; rather they may be the underlying reason for such a link. There were a priori reasons for supposing that smoking, height, weight, and a measure of depression or stress might influence the occurrence of reported back pain in a general population sample. A number of epidemiological studies have reported a link between smoking and back pain, which shows a "dose-response" relationship, ${ }^{145}$ and there is evidence from twin studies of a direct effect of smoking on disc height. ${ }^{16}$ Biologically plausible explanations of the association between smoking and back pain, particularly those related to the effect of smoking on nutrition of the disc, have been reviewed by Ernst. ${ }^{17}$ Associations between back pain and anthropometric variables and psychological factors have also been reported before and are biologically plausible. ${ }^{61819}$ We have confirmed these in this dataset. Since there were social class, income, and education differences in smoking, body mass index, and GHQ scores, such factors might have explained the observed association between back pain and socioeconomic measures. After adjusting for these variables in the multivariate analysis shown in table 4, however, there was little change in the crude estimates. Our conclusion is that in this popu- lation socioeconomic differences in the reporting of back pain cannot be explained by smoking, body mass index, or depression.

It was not unexpected to find that a measure of occupational status such as the Registrar General's classification indicated a link between manual labour and back pain in men. There is evidence to support the notion that those who handle heavy weights are at higher risk than those who do not. ${ }^{4}$ Yet there is also evidence to link car driving and sedentary work with back pain. ${ }^{20}$ The increased reporting of back problems by manual workers compared with non-manual workers suggests that the influence of manual work in the adult male general population is stronger than the risk of sedentary work.

A criticism of traditional social class categories is that they are based on the range of male occupations, and do not take account of the condition of female labour, particularly domestic workloads. This may explain the lack of correlation between reported symptoms and occupational social class in women in a study of low back pain in eight areas of Britain: social class in women was based, as in the Health and Lifestyle Survey, on the husband's occupation. ${ }^{9}$ In the present study those classified as "housekeepers" were at higher risk of back pain than those who went out to work. At the very least this points to the need to study domestic workloads as well as the nature of occupation outside the home.

Other measures of social environment and lifestyle may be more appropriate in women. The strongest association with reported back pain in women among the various measures which we examined was for household income. This was independent of education and husband's occupational class. The absence of a similar link in men suggests that occupational hazards, measured more directly by social class in men than in women, may overwhelm other aspects of socioeconomic grouping in the male workforce.

The evidence from the Royal College of General Practitioners' Third Morbidity Survey of consultations in primary care supports the idea of there being socioeconomic influences on back problems. ${ }^{210}$ This survey involved the recording of all reasons for consultation during a one year period (1981-82) in 138 volunteer general practices. The association between consultation and Registrar General's social class grouping is shown for all conditions and for back pain separately (figure - adapted from the published data). The standardised patient consulting ratio (SPCR) for any group represents the likelihood that they consulted with the condition in question at least once during the survey year, relative to all patients in the survey. The SPCRs shown take into account any age differences between the classes. The sharper gradients for back pain here, compared with the social class figures from the Health and Lifestyle survey, imply that part of the social class effect is related to the propensity to consult a doctor given the symptom of back pain. Possible explanations for this include severity of symptoms or the 

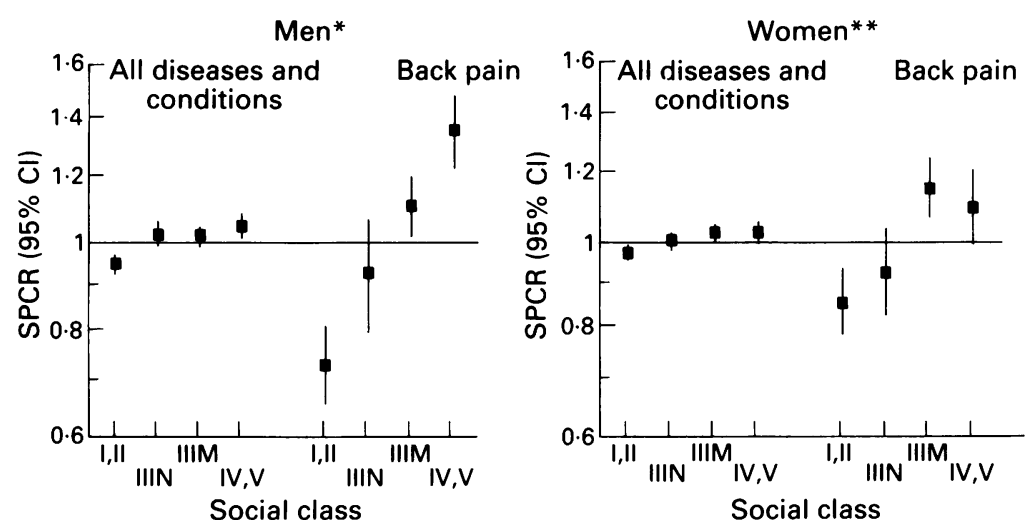

General practice consultations in relation to social class. SPCR $=$ standardised patient consulting ratio. * Registrar General's classification; ** classified by husband's occupation. better off in society. While the aetiological importance of this remains uncertain, back pain affords a clear example of the unequal experience of morbidity in our society.

This analysis was based on the Health and Lifestyle Survey, which was entirely the work of the team headed by Dr Brian Cox. The Economic and Social Science Resource Centre of the University of Essex arranged access to the data. We thank Brian Gratton, Alan Tice, and Owen Stewart for their work on data preparation, and Lesley Jordan for the typescript.

1 Townsend P, Davidson N. Inequalities in health: the Black report. Harmondsworth: Penguin, 1982.

2 Royal College of General Practitioners, Office of Population Censuses and Surveys, Department of Health and Social Security. Morbidity statistics from general practice 1981-2. Locurity. Morbidity statisti

3 Martin J, Meltzer H, Elliot D. The prevalence of disability among adults. OPCS surveys of disability in Great Britain. among adults. OPCS surveys of disabi

4 Walsh K, Cruddas M, Coggon D. Interaction of height and mechanical loading of the spine in the development of low-back pain. Scand $\mathcal{f}$ Work Environ Health 1990;17:420-4

need for sickness certification. Walsh et al, in their population based survey, also found a social class gradient in consultations for low back pain which was independent of severity. ${ }^{9}$ The much weaker association of social class with consultation for all conditions combined, also shown in the figure, argues against general consultation behaviour being responsible for the social class gradient in back pain consultations. However, variations in consultation behaviour in back pain sufferers cannot explain the socioeconomic gradients for reporting back pain which we have shown in this paper based on the Health and Lifestyle Survey. There are likely to be other aspects of environment and lifestyle which influence the experience of back pain.

What might these differences be? If we accept that most of the risk in men may be occupational, then it is possible that physical loads in the workplace or in the home may be responsible for the link with income and education in women. Alternatively, other social class differences which were not explored here, such as diet, parity, and use of oral contraceptives, may be relevant. ${ }^{21} 22$ There may be direct effects of social disadvantage on pain expression, behaviour, and chronicity. ${ }^{6}$ The findings of the prospective Boeing study in America raised the possibility that dissatisfaction with working conditions may directly influence the likelihood of reporting back pain. ${ }^{19}$

Regardless of the explanation, it seems clear that the poorer and more socially disadvantaged groups have a proportionately higher burden of this disabling symptom than the
5 Deyo RA, Bass JE. Lifestyle and low-back pain. The influence of smoking and obesity. Spine 1989;14:501-6.

6 Svensson H-O, Andersson GBJ. The relationship of lowback pain, work history, work environment, and stress. Spine 1989;14:517-22.

7 Kelsey JL, Golden AL, Mundt DJ. Low back pain/prolapsed lumbar intervertebral disc. Rheum Dis Clin N Am 1990;16:699-716.

8 Cox BD. Health and lifestyle survey 1984-85 (computer file). ESRC data archive. Colchester, 1988.

9 Walsh K, Cruddas M, Coggon D. Low back pain in eight areas of Britain. $f$ Epidemiol Community Health 1992;46:227-30.

10 Royal College of General Practitioners, Office of Population Censuses and Surveys. Department of Health: Morbidity statistics from general practice, 1981-2. Third national study: socio-economic analyses. Series MB5, No 2. London: HMSO, 1989.

11 Registrar General. Classification of occupations. London: HMSO, 1980.

12 Goldberg D, Williams P. A user's guide to the General Health Questionnaire. Windsor: NFER-Nelson, 1988

13 Baker RJ, Nelder JA. The GLIM system release 3. Oxford: Numerical Algorithms Group, 1978.

14 Frymoyer JW, Pope MH, Constanza MC, Rosen JC, Goggin JE, Wilder DG. Epidemiologic studies of low-back pain. Spine 1980;5:419-23.

15 Heliovaara M, Makela M, Knekt P, Impivaara O, Aromaa A. Determinants of sciatica and low-back pain. Spine A. Determinants Kaprio J, Koskenvuo M. Smoking and lumbar intervertebral disc degeneration: an MRI study of identical twins. Spine 1991;16:1015-21

17 Ernst E. Smoking, a cause of back trouble? Br 7 Rheumatol 1993;32:239-42.

18 Biering-Sorensen F. Physical measurements as risk indic1984;9:106-19.

19 Bigos SJ, Battie MC, Spiegler DM, et al. A prospective study of work perceptions and psychosocial factors affecting the report of back injury. Spine 1991;16:1-6.

20 Andersson GBJ. Epidemiologic aspects of low back pain in industry. Spine 1981;6:53-60.

21 Fast A, Shapiro D, Ducommun EJ, Friedmann LW, Bouklas $\mathrm{T}$, Floman Y. Low-back pain in pregnancy. Spine las T, Floman 1 .

22 Symmons DPM, van Hemert AM, Vandenbroucke JP Valkenburg HA. A longitudinal study of back pain and radiological changes in the lumbar spines of middle-aged women. I: Clinical findings. Ann Rheum Dis 1991;50:15861 .
16 Battie MC, Videman T, Gill K, Moneta GB, Nyman R, ators for low-back trouble over a one-year period. Spine 